Those rights came in handy in another deal. The CFF had invested about $\$ 25$ million in a recombinant enzyme that could treat pancreatic deficiencies in people with cystic fibrosis. When the developer, Altus Pharmaceuticals in Waltham, Massachusetts, confessed that it could not afford a phase III clinical trial, the foundation snatched up the licence to the patent and shopped around for a new taker.

The technology ended up with Eli Lilly, a drug firm based in Indianapolis, Indiana. The foundation then sold off its royalty rights, funnelling the money into another programme. The recombinant enzyme came up for approval this year, but the Food and Drug Administration has requested further clinical trials.

Philanthropic organizations don't always go unchallenged: universities and companies can chafe at handing over intellectualproperty rights. "Some philanthropies are getting more aggressive and greedy," says Jeffrey Quillen, a lawyer at the law firm Foley \& Hoag in Boston, Massachusetts, who represents start-up companies and university spin-outs. "They see what big pharma gets from these deals and they decide they want stock or co-ownership of intellectual property, too." Some nonprofits reduce their intellectual-property demands to ensure that the project doesn't stall because of disputes.

There is also strife when it comes to sharing royalties. "It's tough, but we'll do it sometimes," says Lita Nelsen, director of technology licensing at Massachusetts Institute of Technology in Cambridge. For example, the university might agree "if the foundation shares in the patent costs". Charities, for their part, tend to resist compensating universities for the 'indirect costs' that might result from a grant — which range from utilities to administrative support. That, notes Nelsen, adds to frustration in negotiations. "They think they're giving us money, but they're costing us," she says.

For the charities, royalties can help to fill the void left by the economic crisis. "Traditional fund-raising is still down for us," says Robert Beall, president of the CFF. "We took the Lilly royalties and put them right back into research - that's what we intend to do to make up for the deficit." The foundation reported more than $\$ 53$ million in royalty revenues last year.

But despite growing awareness of the importance of royalties and intellectual property, Schaner says that some non-profit organizations still give the issue short shrift. "Often, charities don't think past the first year or two when the grant is being made," he says. "They're so accustomed to clinical failures that they don't put enough emphasis on, 'We might have a success, and what happens then?'” $\square$ SEE EDITORIAL P.266

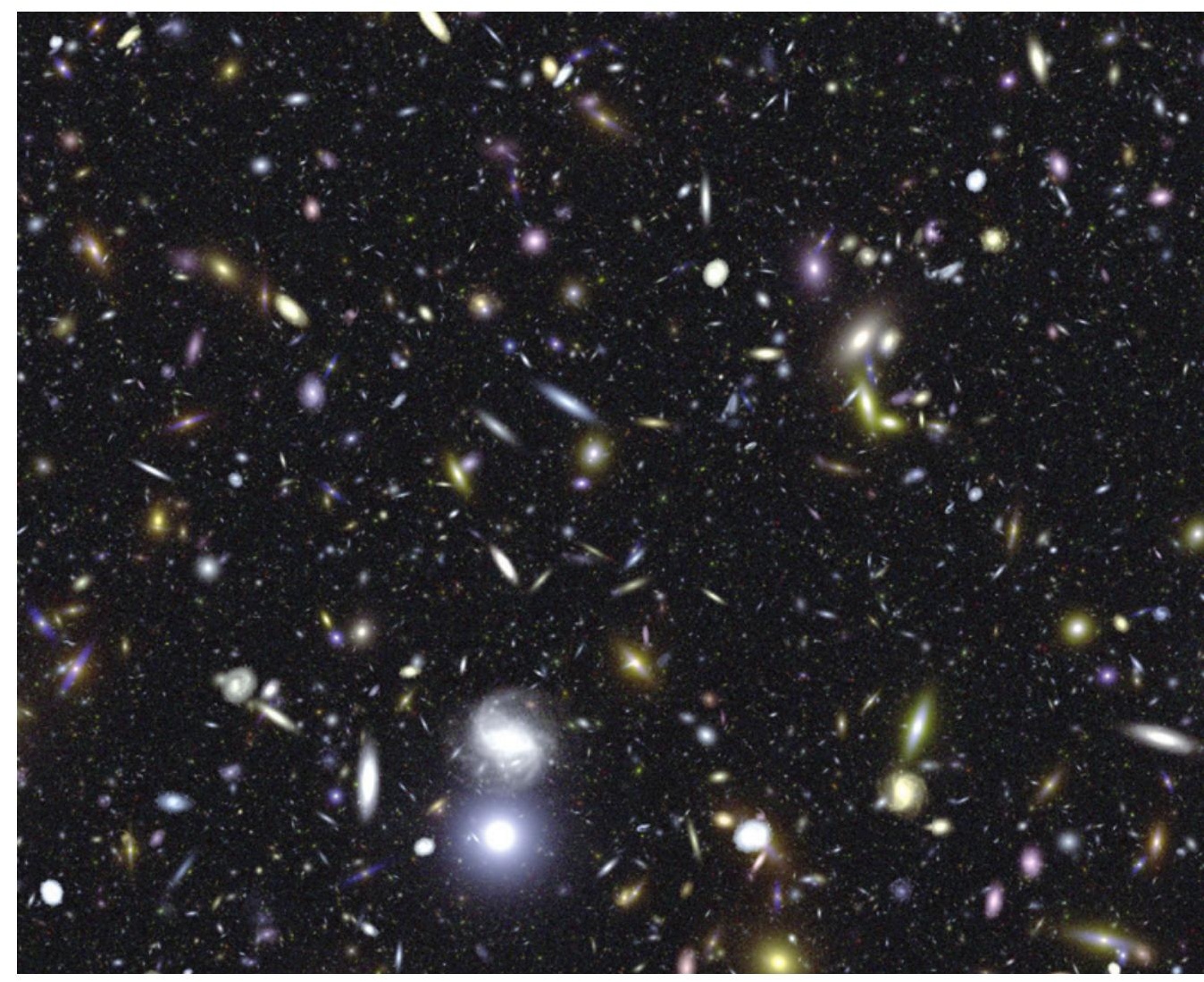

A simulated deep-field image of galaxies like those the James Webb Space Telescope might observe.

\title{
SPACE SCIENCE
}

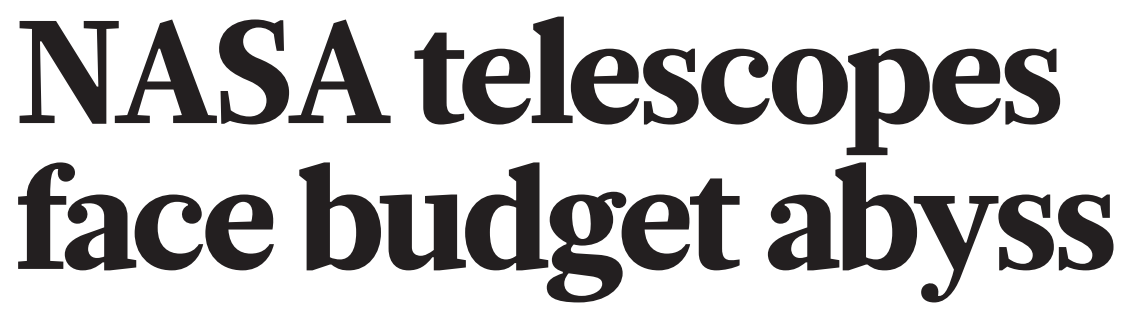

\section{Flagship missions at risk as astrophysics funding shrinks.}

\section{BY ERIC HAND}

A s the space shuttle glides through its final week, another arm of the US space programme faces a bleak future. Astrophysics was once NASA's highestfunded science division and, with the Hubble Space Telescope, a long-time public-relations winner. But its two flagship telescope missions, ranked as the highest priorities for US astronomy, are now under threat as budget constraints start to bite.

Stung by spiralling costs and charges of mismanagement, the James Webb Space Telescope (JWST) - Hubble's long-awaited successor - is now seen by some critics as too expensive to fly. And the Wide-Field Infrared Survey Telescope (WFIRST), which would hunt for exoplanets and probe the poorly understood phenomenon known as dark energy, may take too long to develop to be worthwhile. Added to that, the astrophysics division is facing a budget crunch while other science divisions within the agency weather the fiscal storm and even come out ahead.

"Clearly there's strong support for science," astrophysics director Jon Morse said at an advisory panel meeting on 13 July as he reviewed his division's place in the scientific pecking order at NASA. "The change here is about priorities."

With support from President Barack Obama, the agency's Earth science budget is at an all-time high. Over the next four months, the planetary science division is due to launch three major missions: to the Moon, to Mars and to Jupiter. And the heliophysics division plans to send a probe plunging into the blistering atmosphere of the Sun, closer than ever before. But because the overall NASA science budget is relatively flat, something had to give. Since 2008, astrophysics funding has plunged 


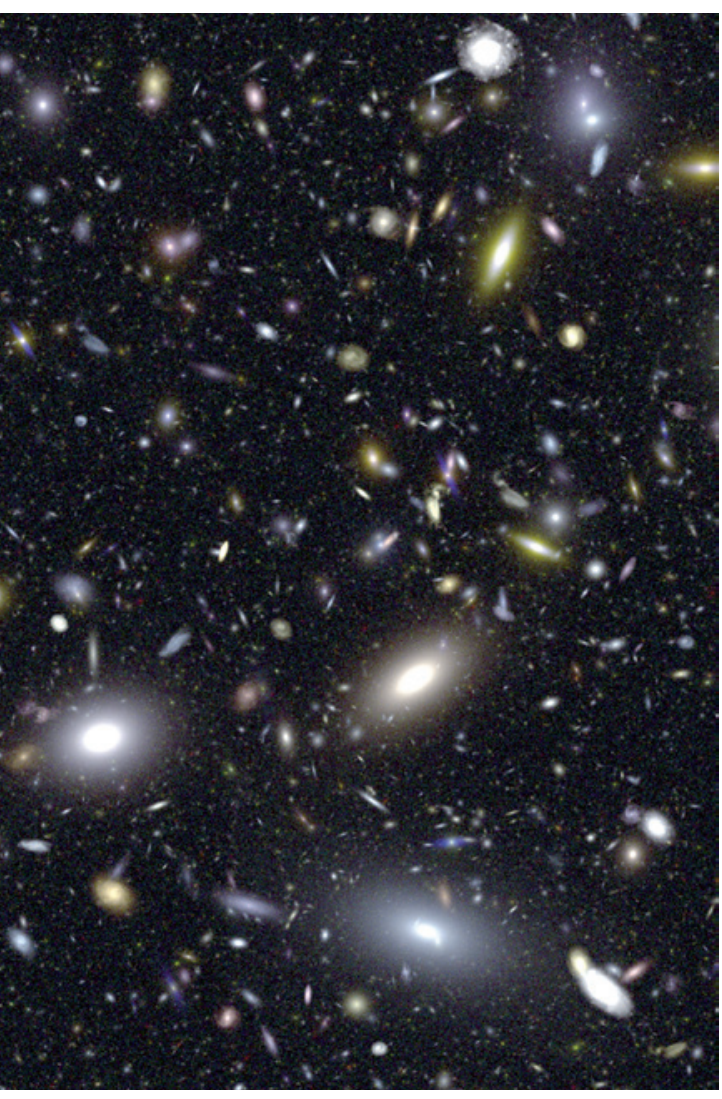

$\underset{1}{4}$ relative to other NASA science (see 'Falling ${ }^{\frac{5}{2}}$ fortunes') - and relative to physics and astronomy funding at other agencies.

"We're the orphan of the agency," says Alan Boss, chairman of the advisory panel and an astronomer at the Carnegie Institution for Science in Washington DC.

In Congress, the division faces outright hostility. While Boss lamented the budget trends at last week's meeting, a House appropriations committee was endorsing a bill that would cancel funding for the JWST. By all accounts, the 6.5-metre telescope will be at least as important to astronomy as Hubble has been. Designed to operate in the infrared, where the oldest celestial objects shine, the JWST could peer back to the Universe's first stars. It could also use the exquisite resolution offered by the vacuum of space to spot Earthlike planets. "Every once in a while, NASA does something that changes the game," says Michael Turner, director of the Kavli Institute for Cosmological Physics at the University of
Chicago, Illinois. "JWST is in that category."

But the cost of the JWST has also changed the game. In November, an independent panel called in by Congress blasted the project for mismanagement. It found that the telescope's price tag had ballooned to US $\$ 6.5$ billion and that its launch date would have to be delayed to 2015 (see Nature 468, 353-354; 2010).

Even that projection seems to have been too optimistic. At the advisory panel meeting, Rick Howard, the recently installed JWST programme director, said that following his overhaul of the mission, the telescope will now launch in 2018 at the earliest.

"Of course people are disappointed," says project scientist John Mather of the Goddard Space Flight Center in Greenbelt, Maryland, which is managing the project. "I wanted it sooner, too." Although the extra time should be enough to resolve technical setbacks that have slowed the project, it also raises costs, as engineers and scientists must be employed for longer. Howard would not reveal exactly what the new price tag was, but he acknowledged that it would be more than $\$ 6.5$ billion. About $\$ 3$ billion has been spent already.

To get the mission back on track, NASA replaced all of the JWST's senior managers and put Howard at the helm. So far, he says, all of the telescope's 18 mirror segments have been polished and assembled. Engineers have also determined why some of the telescope's infra-

\section{"We're certainly more vulnerable than ever."}

red detectors have

begun to degrade. The bad detectors are being replaced at an additional cost of $\$ 40$ million to $\$ 50$ million, Howard says.

Many expect that the project's political defenders, such as Senator Barbara Mikulski (Democrat, Maryland), will be able to fend off the immediate threat in Congress. Garth Illingworth, an astronomer at the University of California, Santa Cruz, who was on the independent panel that reviewed the JWST, says that his real worry is whether the telescope will receive the massive infusion of funds it needs to get off the ground by 2018 . The White House is currently requesting $\$ 355$ million for the project in 2012, and slightly more each year for the next four years. At those levels, Illingworth says, the telescope will never launch.

\section{FALLING FORTUNES}

Cuts to NASA's astrophysics division would see it fall from being the highest-funded science division to one of the least funded within the agency.

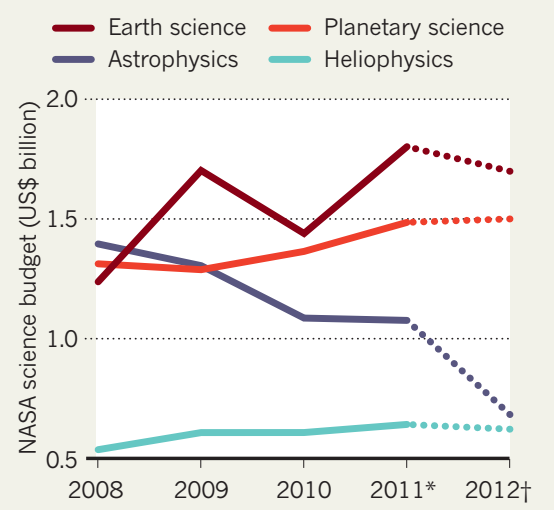

*From the presidential budget request.

†From a US House of Representatives spending bill, which may change when reconciled with the Senate.

If the JWST is delayed yet again it will further imperil WFIRST, the next big astrophysics mission. The project, declared as the top priority in last year's decadal review of US astronomy by the National Academy of Sciences, is designed to measure the effects of dark energy - thought to be accelerating the expansion of the Universe - and to monitor distant stars for signs of exoplanets. But the rising cost of the JWST, together with NASA's declining astrophysics budget, could mean that the \$1.6-billion project might not get off the drawing board, let alone the launch pad.

The progress of a European Space Agency proposal to launch a similar telescope, called Euclid, by 2017 puts WFIRST in an even bigger bind. The proposal, submitted on 14 July, will face a final selection round in October. "If Euclid happens and is as good as they say, then I'm not sure [WFIRST] makes sense," says Turner.

Morse maintains that the division's budget woes will not affect other, smaller astrophysics missions scheduled for the next few years, but with two flagship missions in jeopardy that is small consolation to many astrophysicists.

"We're certainly more vulnerable than ever," says Boss, who worries that the seriousness of the situation may be lost on those outside the astrophysics community. "Maybe people are saying, 'They've got Hubble; that's all they need."
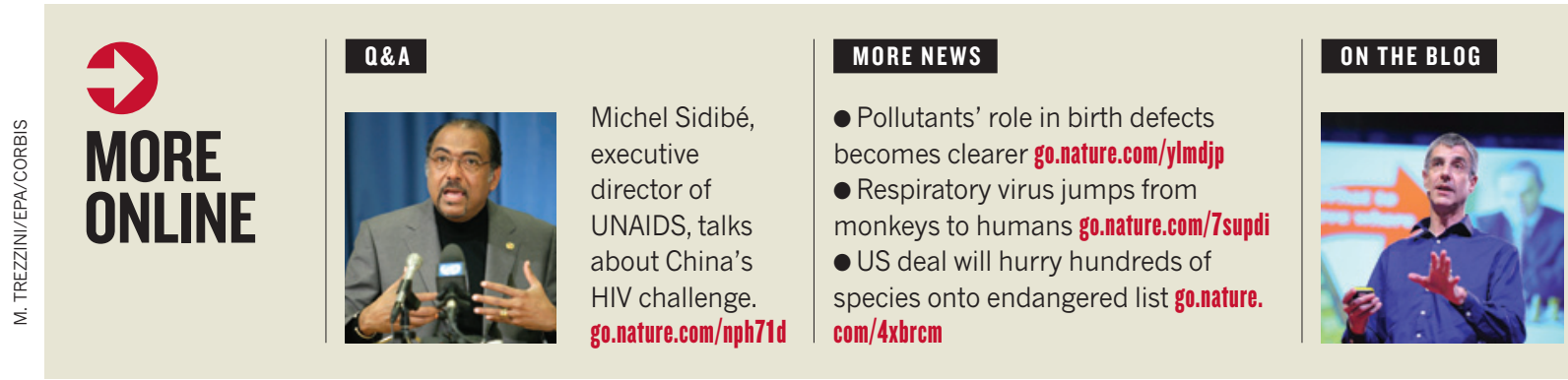

TED conference: from the power of hugs to atheism 2.0 go.nature.com/ j†58q8 